Fanum

Sociológico
Forum Sociológico

Série II

21 | 2011

Transformação urbana

\title{
Urbanizando pelo lazer: o caso do Algarve
}

João Martins

\section{OpenEdition}

Journals

Edição electrónica

URL: https://journals.openedition.org/sociologico/395

DOI: 10.4000/sociologico.395

ISSN: 2182-7427

Editora

CICS.NOVA - Centro Interdisciplinar de Ciências Sociais da Universidade Nova de Lisboa

Edição impressa

Data de publição: 1 dezembro 2011

Paginação: 65-73

ISSN: 0872-8380

\section{Refêrencia eletrónica}

João Martins, «Urbanizando pelo lazer: o caso do Algarve », Forum Sociológico [Online], 21 | 2011 ,

posto online no dia 05 setembro 2012, consultado o 29 março 2022. URL: http://

journals.openedition.org/sociologico/395 ; DOI: https://doi.org/10.4000/sociologico.395

Este documento foi criado de forma automática no dia 29 março 2022.

(c) CICS.NOVA 


\title{
Urbanizando pelo lazer: o caso do Algarve
}

\author{
João Martins
}

\section{Introdução: Turismo e Urbanização}

1 A apropriação territorial turística na região do Algarve levanta, segundo o nosso ponto de vista, duas grandes linhas de investigação nos estudos urbanos. Em primeiro lugar, a compreensão dos processos de territorialização do consumo e do lazer concebidos como direitos sociais nas sociedades contemporâneas, da sua centralidade e da constituição de um espaço de materialização destas aspirações. As alterações no mercado de trabalho e um aumento progressivo do tempo livre de estratos sociais cada vez mais diversificados operaram uma alteração significativa na organização funcional e económica dos territórios urbanos, orientando-os no sentido da promoção do consumo. 0 turismo, o entretenimento e os usos lúdicos do território tornam-se áreas fundamentais de investimento financeiro e laboral (Baptista, 2005; Hannigan, 1995, 2010a e 2010b; Urry, 2002; Mullins, 1991; Gladstone, 1998; Gladstone e Fainstein, 1999). Face às transformações da própria actividade turística que se materializaram no desejo de contacto simbólico entre o turista e o espaço visitado, assistimos a uma especialização turística das diferentes cidades através da promoção de narrativas identificadoras das suas populações, de um corpo discursivo que levanta a sua autenticidade, particularidade e originalidade em relação a contextos turísticos concorrentes (Gladstone e Fainstein, 1999).

2 Em segundo lugar, uma análise orientada para a compreensão dos processos de urbanização em Portugal e numa área específica, o Algarve, que apesar da tradição municipalista das suas principais cidades, sofreu um processo tardio e acelerado de urbanização no sentido do turismo a partir da década de 1960, acompanhando o desenvolvimento sentido na Andaluzia e restante bacia do Mediterrâneo (Brito, 2009). Sendo uma área marcada pela agricultura de subsistência, pescas e indústrias de transformação de produtos regionais até à década de 60 , ao analisarmos a 
reconfiguração urbana destes territórios estaremos perante um exemplo de urbanização promovida no sentido da reconversão de áreas deprimidas económica e socialmente, que neste caso privilegiou um modelo baseado no aproveitamento de belezas naturais (o clássico Sol e Mar).

Este processo não está enquadrado no modelo clássico de reconfiguração produtiva industrial-turística decorrente do primeiro choque petrolífero na década de 70 e da reorientação da indústria a oriente, que assistimos em grandes cidades mundiais como Nova Iorque, Londres, Paris, Amsterdão ou mesmo, numa escala mais reduzida, Lisboa. Apesar da progressiva diminuição do parque industrial existente na região algarvia e da reconversão territorial de áreas piscatórias em espaços de fruição turística, percepcionamos um quadro de urbanização rápida em que os serviços, neste caso o turismo, são o seu elemento promotor. Podemos até dizer que o Algarve e a restante baía mediterrânea revelam um processo original de urbanização pelo lazer e pelo consumo, determinando a sua forma urbana e até de certa forma uma exclusividade no processo de urbanização.

\section{Uma caracterização da região}

4 Para poder compreender a importância desta região no contexto nacional recorremos ao Anuário Estatístico da Região Algarve (INE, 2010) no sentido de radiografar a região. Escolheram-se dados pertencentes a três dos quatro capítulos desta publicação: (i) Território, (ii) Pessoas e (iii) Actividade Económica. Ao mesmo tempo foi necessário cruzar estes dados com o censo de 1960 e os dados provisórios do censo de 2011, assim como à literatura existente nas áreas dos estudos urbanos e do turismo, contextualizando alguns dos resultados.

\section{Território (i)}

5 O indicador escolhido neste capítulo é denominado "Usos do Solo identificados em PMOT", que divide o território municipal nas seguintes categorias: "Urbano, Equipamentos e Parques Urbanos, Industrial e Turismo" (INE, 2011a: 39). Uma primeira leitura indica que $20,4 \%$ do território integrado em PMOT tinha uma orientação turística. Este valor levar-nos-ia a pensar que o peso do turismo na região não seria determinante, sendo que quase $80 \%$ do restante território não teria essa ocupação. Os contributos de Brito (2009) e Soares (1997) acerca da importância territorial do Turismo no Algarve, a observação dos territórios, do seu edificado e das suas utilizações revelam uma outra realidade, em que as utilizações turísticas do território são mais alargadas. $O$ desencontro entre a percentagem de território dedicada directamente ao turismo e o seu peso real poderá ser explicado através da percepção de formas de urbanização no sentido do turismo de natureza não formal. Um exemplo citado pelos autores é o peso e efeito da implantação de segundas habitações em áreas residenciais (urbanas), não sendo desta forma contabilizadas e integradas no circuito formal da actividade turística. Brito (2009) vai mais longe, ao indicar que o Plano Regional de Ordenamento do Território de $1991^{2}$ criou uma situação caricata, reduzindo as áreas de implantação do turismo, sendo que a actividade imobiliária continuou em áreas de natureza urbana ou, como o autor refere, em zonas dispersas em redor dos grandes centros urbanos e turísticos. Nascem aqui dois problemas: densificação e dispersão, fomentados pela 
ineficácia no controlo dos processos de urbanização, criando zonas urbanas (residenciais) em que a ocupação é também turística, mas sem as diferenciarem claramente. Resultante da elevada discricionariedade na atribuição de licenças de construção, surge um movimento duplo: concentração nos centros urbanos turísticos consolidados como Albufeira e a dispersão da construção nos territórios mais afastados da linha do litoral como Loulé.

Soares (1997) apresenta uma forma interessante de compreender o processo de construção de áreas de natureza urbana polinuclear. Estas são formas de alojamento que se desenvolveram em duas classes, "o alojamento turístico classificado e a residência secundária" (Soares, 1997: 26). As primeiras são reguladas centralmente pelo Governo como actividade produtiva importante, a mais relevante no que toca às exportações (implicando a entrada de capitais do exterior), com um enquadramento fiscal específico. No segundo caso, em resultado de processos de urbanização dos territórios no sentido turístico, surgem um conjunto de propostas de acomodamento dos turistas, num circuito económico paralelo, que não fazem quaisquer contribuições fiscais específicas (para além dos impostos de natureza municipal) e que estão sob a alçada das municipalidades. No nosso ponto de vista, esta duplicação do alojamento orientado ao lazer (formal e informal) levanta um conjunto de controvérsias públicas, principalmente no debate muito mediatizado sobre o suposto desordenamento territorial no Algarve, nomeadamente no que se refere à utilização dos solos, à sua transformação em estrutura urbanizável e às relações entre os promotores imobiliários deste tipo de equipamentos e os reguladores públicos que os regulam. Segundo a autora, já em 1980, quase duas décadas depois do início da abertura turística da região, a utilização de residências secundárias já chegava aos $70,2 \%$, um valor que é claramente descritivo do fenómeno existente. Em 1990 esse valor subia para 74,7\% (Soares, 1997: 26).

\section{População (ii)}

7 Neste capítulo são vários os indicadores que nos permitem perceber mais um pouco sobre a região. No que toca aos "Indicadores de população por município" (INE, 2011a: 63) percebemos que a região apresenta globalmente uma densidade populacional baixa face ao total nacional $\left(87,6 \mathrm{hab} / \mathrm{Km}^{2}\right.$ face a $115,4 \mathrm{hab} / \mathrm{Km}^{2}$ em Portugal), mas que as cidades de Albufeira ou mesmo Faro apresentam valores muito superiores, com 266,7 $\mathrm{hab} / \mathrm{Km}^{2}$ e $290,4 \mathrm{hab} / \mathrm{Km}^{2}$ respectivamente (INE, 2011a: 63), em nosso entender sinais de concentração de populações ligadas ao turismo por via do trabalho. No caso de Albufeira de forma directa, e no caso de Faro - capital da região e local de concentração de serviços, instituições públicas e privadas - de forma directa ou indirecta.

8 Ainda neste capítulo analisámos a "Proporção de casamentos entre portugueses e estrangeiros" que, se no país apresenta uma média de 10,8\%, no Algarve sobe para $20,9 \%$, ou mesmo $28,3 \%$, em Albufeira. Cruzando a "População estrangeira com estatuto legal de residente em 2010" (INE, 2011a: 67) e a "População residente por Município" (INE, 2011a: 65), percebemos que a percentagem de população estrangeira face ao total regional é superior no Algarve $(16,41 \%$, sendo mais representadas as comunidades brasileira e britânica) face à média nacional (4,1\%), sendo que mais uma vez é superior em Albufeira $(27,8 \%)^{3}$. Para perceber o nível de atracção associado usámos no indicador "População estrangeira que solicitou estatuto legal de residente por 100 habitantes" (INE, 2011a: 64) que é de 1,5\% no Algarve, 2,5\% em Albufeira e 0,5\% no total nacional. 
Estes dados relacionados com a imigração identificam a região como uma área de penetração de migrantes, um dos elementos fundamentais dos processos de transformação urbana no sentido do turismo, atraídos pelo alargamento da actividade produtiva e deste modo do mercado de trabalho.

9 No que toca ao total da população residente e agora recorrendo à comparação entre os dados do Censo de 1960 e os resultados provisórios do Censo de 2011, percebemos algumas mudanças significativas. Em primeiro lugar, um aumento de $18 \%$ na população total nacional, que na região algarvia foi de $43 \%$, sendo que no caso de Albufeira a população residente mais que duplicou, e em Faro esse crescimento foi de 79,4\%. Este aumento populacional materializou-se no aumento generalizado dos alojamentos existentes com um crescimento na ordem dos $256,9 \%$ na região, $738,5 \%$ em Albufeira e $245 \%$ em Faro, face a um aumento ao nível nacional de $126 \%$. No que toca aos edifícios em Portugal o seu aumento foi de $18,74 \%$ nestas cinco décadas, sendo que no Algarve foi de $55 \%$. Mais uma vez se expressa o processo de concentração de populações em redor da região desde o início da actividade turística que assinalámos através da abertura do Aeroporto Internacional de Faro e da instalação das primeiras grandes instalações hoteleiras orientadas para o turismo na década de 1960.

\section{Actividade Económica (iii)}

Por fim analisamos os indicadores reunidos no capítulo "Actividade Económica" (iii) (INE, 2011a: 157). Os primeiros dados a ter em conta são os indicadores de contas regionais que poderão dar-nos mais algumas pistas acerca do dinamismo económico da região. A população activa da região representa $4 \%$ do total nacional, um valor de 17,8 milhões de euros per capita em relação a 16,19 milhões para o resto do país. Apresenta $67,04 \%$ de trabalhadores por conta de outrem, $45 \%$ com contrato sem termo (mais baixo face ao total nacional de 53,06\%) e uma taxa de desemprego de $13 \%$ no $3 .^{\circ}$ trimestre de 2011, uma das mais altas no contexto português. Apresenta ainda uma remuneração média mais baixa que a média nacional (17,60/19,50 de milhares de euros), apesar de o PIB per capita ser superior. Face aos diferentes sectores que compõem a economia da região e usando o indicador "VAB em \% do total da região" (INE, 2011a: 158), percebemos que o sector 4, que aglomera o comércio, alojamento e restauração, apresenta o valor mais alto com $34,8 \%$ dos valores apurados, o que facilmente se identifica com a actividade principal: o turismo. Ao mesmo tempo será importante ainda notar a importância do sector 3, "Construção", com $11,8 \%$, que poderá ser explicado pela enorme pressão construtiva vinda da opção turística, assim como o sector 7, "Actividades imobiliárias", com 11,4\%. Pegando noutro indicador, de natureza absoluta, o "VAB em milhões de euros pelas diferentes actividades" (INE, 2011a: 160), percebemos que aquelas que apresentam maiores ganhos são as "Actividades Imobiliárias" com 147,72 milhares de euros, as "Actividades financeiras e Seguros" com 97,62 milhares de euros, e as "Actividades de informação e comunicação" com 94,18 milhares de euros. Este processo associado à construção pode igualmente ser visto através dos "Valores Médios de Avaliação Bancária dos Alojamentos", que em Portugal são em média 1223 euros $/ \mathrm{m}^{2}$, sendo no Algarve 1531 euros $/ \mathrm{m}^{2}$.

Passemos aos dados directos referentes ao turismo (INE, 2011a: 271). Um primeiro indicador é o tráfego aeroportuário, representando a região $13,54 \%$ dos voos em 2010, sendo o seu aeroporto exclusivamente dedicado a voos com destinos europeus. Quanto 
à "Capacidade de alojamento por 1000 habitantes" 25,7; subindo extraordinariamente para 226,20 no Algarve e mesmo 1010,5 em Albufeira, 36,8 em Faro e 197,6 em Loulé, demonstrando a existência de uma estrutura imobiliária orientada para a recepção de turistas. Outra medida interessante está ligada ao indicador "Hóspedes por habitante", que, se em Portugal é de 1,3, no Algarve é de 6,6 . Teremos de ter em conta que estes valores não agregam toda a população que visita o Algarve, ficando de fora todos os turistas que informalmente acedem a instalações não classificadas como alojamento turístico ou alojamento local. Face à oferta formal de alojamento, percebemos que o Algarve representa 20,5\%, sendo que Albufeira representa $7 \%$ do total nacional em termos de estabelecimentos. No que toca aos "proveitos de aposento" em milhares de euros, percebemos que a região representa $39,35 \%$ de todos os ganhos.

Desde as primeiras ofertas turísticas que se localizaram junto de áreas marcadas pela beleza natural (praias, montanhas) até à dispersão de casas em regime de segunda habitação, timesharing, ou mesmo da tipologia em apart-hotel, o caminho foi longo, alterando-se progressivamente uma das dinâmicas mais importantes neste sector, o alojamento. O Algarve apresenta-se como um caso exemplar para pensar estes fenómenos. Desde as primeiras ofertas hoteleiras descritas por Brito (2009) no seu livro Território e Turismo no Algarve, até à criação de pensões e albergues em zonas litorais de utilização piscatória, passando pela criação de um parque habitacional disperso e em regime de segunda habitação ou de aluguer ilegal, o território no Algarve materializa claramente a tentativa de criação de habitações com vista de mar, ou localizadas numa zona interior, mas que apresentam boas ligações às principais cidades, praias e actividades comerciais de entretenimento.

\section{A essência urbana do turismo}

Enquanto forma de mobilidade fomentada pelo desejo de viajar e de experienciar diversas formas de lazer, o turismo apresenta-se como um fenómeno central nas sociedades contemporâneas. Nesse sentido, esta actividade torna-se fundamental ao nível económico através do investimento e reprodução de capital financeiro; da criação de um sector laboral marcado pela flexibilidade, polivalência e precariedade ou mesmo da substituição de sectores produtivos tradicionais como a agricultura ou as pescas pela denominada "monocultura do turismo", criando grandes áreas de natureza urbana exclusivamente orientadas para o consumo e o entretenimento. Estas actividades têm um efeito preponderante nos usos do território e na sua natureza urbana, promovendo processos de Urbanização Turística (Mullins, 1991; Hannigan, 1995; Gladstone, 1998; Leite, 2008). Ao nível social e especificamente no que se refere aos processos de ascensão social de uma petite bourgeoisie (Mullins, 1991: 337), percebemos uma forte relação entre o Turismo e a criação de pequenas elites locais, que poderão ou não estar ligadas a circuitos internacionais. Como actividade de elevada rentabilidade, fomentadora de processos migratórios e de alargamento do mercado de trabalho, terá igualmente um efeito progressivo nos restantes estratos sociais, amenizando diferenças sociais e de acesso ao consumo entre os agentes, não significando que não sejam ao mesmo tempo espaços de concentração de pobreza extrema (Gladstone, 1998). Ao nível cultural, tanto a Antropologia como a Sociologia do Turismo têm produzido material extensivo acerca da orientação da actividade económica para o contexto urbano, 
promovendo a exploração económica do património construído e imaterial, mas também acerca da forma como se constrói a imagem das cidades (Bryman, 2009, Hannigan, 2010a e 2010b; Gladstone e Fainstein, 1999).

Para podermos pensar os processos de integração de actividades turísticas nos territórios do Algarve, necessitamos de abordar um pouco as origens dos estudos sobre o turismo. Fortuna e Ferreira (1996) avançam com a pouca preocupação que até aí a Sociologia e restantes ciências sociais deram ao fenómeno turístico, vendo-o como um fenómeno pouco respeitável e digno de investigação científica. A alteração desta preocupação passou pela consecutiva importância que o tempo livre e o seu uso lúdico ganharam na esfera económica e simbólica das sociedades contemporâneas. Esta dinâmica de procura de sensações turísticas encontra-se igualmente associada a uma mitologia do consumo e da mobilidade, uma cidadania que é comum a todos (porque todos têm o direito a viajar), mas que acaba por ser experienciada diferentemente por diferentes grupos sociais, uma vez que nem todos podem aceder ao turismo de gama mais elevada. Percebemos assim que há um elemento nesta equação profundamente contraditório: se por um lado as transformações modernas implicam uma quebra das diferenças sociais, por outro este elemento moderno é frontalmente desmentido através da inexistência de uma democracia económica e de distribuição da riqueza que contraria e impossibilita a universalidade (mais um elemento supostamente associado às sociedades modernas) do acesso a esta faceta de cidadania e deste novo direito social.

Tribe (1997) levanta as características epistemológicas do conhecimento na área do turismo, procurando perceber se esta funciona como um corpo disciplinar (uma rede de conceitos, uma estrutura de investigadores em rede, se produz resultados testáveis e observáveis segundo métodos científicos), ou se é apenas uma área de estudo, um campo de observação de outros fenómenos de dimensão macrossociológica que se reproduziam nos contextos turísticos. A escolha do autor vai para esta última opção, reconhecendo que os Tourist studies utilizam conceitos que não lhe são exclusivos, não construindo de facto uma forma distinta de trabalho teórico. Tribe nota igualmente a enorme influência que as redes de operadores turísticos e gestores na área do turismo imprimem nos estudos sobre o turismo: satisfação dos turistas, a apetência de um local em contexto de competição com outros, a exigência da população na dinamização territorial pelo turismo (à espera da possibilidade da instalação de postos de trabalho); são factores que imprimem uma dinâmica fortemente económica e de gestão de activos em relação ao turismo. A resposta, segundo Mullins (1991), passa por avaliar e analisar a indústria do turismo e os seus protagonistas que permanecem desconhecidos: "A ignorância acerca da oferta dificulta a percepção da natureza do turismo e desse modo as forças sociais que o formam" (Mullins, 1991: 326). Ao mesmo tempo será importante apresentar o contexto desigual e segregacionista da urbanização turística através do reconhecimento de processos de mapeamento da cidade, da implantação dos empreendimentos turísticos em determinadas áreas urbanas, separados de determinados grupos sociais indesejados do famoso cartão postal.

\section{Cidades Turísticas como territórios de consumo}

Para pensar o conceito de Urbanização Turística apresentarei inicialmente o conceito de Território Lúdico e de um modo de vida lúdico, que Baptista (2005) expõe da seguinte forma: 
Economicamente, o turismo (visão lúdica dos usos dos lugares experimentados a experimentar) revaloriza as economias locais na medida em que dá oportunidade às localidades, às regiões, às nações de fazerem uso do seu património de modo a dele tirarem proveito. Contudo é evidente que o mercado, e a hierarquia dos lugares turísticos, sendo altamente competitivo, promove e despromove lugares, havendo a priori condições distintas nas capacidades de dar importância aos lugares e de os publicitar. (Baptista, 2005: 55)

Penso que a citação apresenta um interesse particular quando apresenta o cruzamento do surgimento de um modo de vida, que representa os tempos livres como espaços de evasão desejada e massificada, com a forma como o espaço se reproduz e dá resposta a este anseio.

Face à importância crescente que o consumo ganhou nas sociedades pós-fordistas, parece-nos relevante reler com atenção o texto de Mullins (1991). O autor ressalta a relação assinalada por Saunders no livro de 1986, Social theory and urban question, em que a Sociologia Urbana e a Sociologia do Consumo deveriam ser consideradas um mesmo subcampo de disciplina, indicando igualmente que conceitos como os de suburbanização, gentrificação e cidade pós-moderna deverão ser esclarecidos de modo a podermos analisar a natureza do turismo.

19 O texto de Mullins, com cerca de duas décadas, foi inovador no que toca à abordagem de áreas urbanas construídas unicamente no sentido do consumo, sendo citado por vários autores que criticamente o utilizaram Gladstone (1998), Hannigan (1995) e Leite (2008). Na verdade, apesar das críticas que os vários autores levantaram ao carácter exclusivista do turismo nas Tourist Cities australianas de Mullins, teremos de valorizar a tentativa do autor de singularizar um conjunto de tendências, dinâmicas e especificidades destas áreas urbanas em relação a outras. A maior crítica apontada a Mullins e à utilização do seu legado é a necessidade de contextualização das diferentes cidades turísticas, sendo que algumas das características de uma cidade poderão não se reproduzir totalmente numa outra, não havendo de facto uma colagem total entre o modelo de consumo urbano apresentado pelo autor e a realidade. Não poderemos dizer que o modelo datado historicamente e orientado para a percepção da Gold Coast australiana possa descrever totalmente o processo urbano decorrente nestas quase cinco décadas de turismo no Algarve. Tal como Gladstone (1998) esclarece, é necessário fazer um esforço de contextualização das diferentes escolhas turísticas, percebendo que dominância económica, social e cultural o turismo apresenta em cada uma das cidades, ou se pelo contrário estas cidades integram o turismo como mais uma das suas características entre outras.

20 Mas do que falamos quando abordamos o conceito de consumo? Falamos do "uso que as pessoas fazem de bens e serviços, com este consumo duplamente assegurando a sua sobrevivência pessoal e a continuidade das sociedades" ${ }^{6}$ (Mullins, 1991: 327), integrado numa economia de mercado que promove continuamente a criação de novos bens $\mathrm{e}$ serviços transaccionáveis, de distribuição de massa ou diferenciados como no turismo de natureza ou cultural, influenciando o desenvolvimento

das sociedades ocidentais, introduzindo transformações na estrutura social, criando novos actores sociais, novos custos, novas relações. Até à década de 70 , os desenvolvimentos mais marcantes do consumo na Europa Ocidental estavam ligados aos processos de urbanização promovidos pela intervenção pública, tanto nos campos da habitação (social), como no dos cuidados de saúde ou mesmo da educação. No caso dos Estados Unidos, este processo de expansão deu-se através da suburbanização da 
classe média, da aplicação de modelos de sistematização racional do trabalho, e de um consecutivo aumento nos salários, alargando as formas de consumo. As alterações nos orçamentos públicos em ambos os contextos a partir das décadas de 70 e 80 levaram a uma quebra neste tipo de investimentos de âmbito assistencialista e tendencialmente universalizante; caindo assim o sentido original do próprio conceito.

Estamos perante uma realidade urbana nova, a que Hannigan (2010a), Mullins (1991) e Gladstone (1998) chamam pós-moderna e gentrificada, implicando uma nova estrutura de acumulação do capital, novas formas de transformação do espaço, uma nova sociedade. Social e economicamente, a cidade pós-moderna é descrita simplesmente como aquela que é resultado do fim da manufactura ou mesmo da sua inexistência (como no caso do Algarve), marcada por um sistema flexível de trabalho associado ao pós-fordismo. A indústria foi substituída pela construção associada às FIRE industries (Finance, Insurance, and Real Estate), comércio retalhista, mão-de-obra específica, uma elite de executivos bem pagos, altos níveis de desemprego e subemprego, grandes desigualdades na distribuição da riqueza e, no caso dos EUA, elevados níveis de segregação racial. Uma marca significativa deste processo de transformação social e económica está ligada à promoção da flexibilidade funcional dos trabalhadores, operando em diferentes áreas, respondendo a diferentes escalas de intervenção, caindo assim mais um dos elementos fundamentais do fordismo: a repetição indiferenciada. Estas transformações implicam um aumento da formação dos trabalhadores, assim como dos salários, criando aquilo a que poderemos chamar uma "nova classe média" (Mullins, 1991: 329). Desta forma a cidade turística, como espaço natural e esperado de consumo, apresenta-se como a forma urbana da sociedade pós-moderna:

Noutras palavras, onde a pós-modernidade identifica, conceptualmente, o consumo massificado do prazer, a cidade pós-moderna é a forma urbana da pósmodernidade, uma forma urbana focalizada no prazer. A Urbanização Turística, então, é a mais dramática expressão desta nova forma urbana porque aqui estão cidades inteiras construídas exclusivamente para o prazer. (Mullins, 1991: 330) ${ }^{7}$

o processo liderante desta transformação territorial e social (geralmente) dos centros das cidades e das suas inner cities dá-se através do conceito de gentrificação: nos seus termos territoriais, alterando funcionalmente as características destes espaços; mas também socialmente, operando processos de substituição de classes sociais mais baixas residentes por outras que podem aceder a patamares mais elevados de consumo.

Ao mesmo tempo, o consumo é igualmente apresentado como um símbolo de ascensão social, um símbolo distintivo entre os agentes. Estaremos aqui perante a teoria do "pão e circo", pondo em evidência a forma como os agentes resistem ou não aos apelos do consumo, como o acesso ao consumo poderá influenciar ou não mudanças sociais, transformando-se num elemento determinante na existência de paz social. Sobre este assunto Debord e Ritzer esclarecem:

Esta sociedade que suprime a distância geográfica recolhe interiormente a distância, enquanto separação espectacular. Subproduto da circulação das mercadorias, a circulação humana considerada como um consumo, o turismo, reduz-se fundamentalmente à distracção de ir ver o que se tornou banal. A ordenação económica da frequentação de lugares diferentes é já por si mesma a garantia da sua equivalência. A mesma modernização que retirou da viagem o tempo retirou-lhe também a realidade do espaço. A sociedade que modela tudo o que a rodeia edificou a sua técnica especial para trabalhar a base concreta deste conjunto de tarefas: o seu próprio território. O urbanismo é esta tomada de posse do meio ambiente natural e humano pelo capitalismo que, ao desenvolver-se logicamente 
em dominação absoluta, pode e deve agora refazer a totalidade do espaço como seu próprio cenário. (Debord, 1997: 121)

As novas formas de consumo podem ser vistas como «catedrais do consumo» - isto é, são estruturadas, muitas vezes

com sucesso, para terem um encanto, às vezes até um carácter sagrado, religioso. Para atrair consumidores, estas catedrais de consumo precisam de oferecer, ou pelo menos parecer que oferecem, um conjunto de bens crescente de natureza mágica, fantástica e encantada em que se possa consumir. (Ritzer, 2010: 7)

Para poder compreender o mecanismo de transformação dos territórios no sentido do turismo e de poder compreender a constituição de um espaço orientado para esta actividade no Algarve, recorrerei mais uma vez ao contributo de Mullins (1991) e das características que este associa às cidades turísticas. Tal como enunciado anteriormente, não acreditamos que estas categorias expliquem o fenómeno de turismo na região, mas poderão ajudar-nos a compreender mais um pouco da sua natureza territorial, como uma grelha de leitura da realidade urbana. Deste modo não estaremos a reafirmar simplesmente o modelo e a colá-lo à realidade que observamos, mas sim a possibilidade de pensar o território ao redor de um conjunto de variáveis, que segundo o nosso ponto de vista avançam na caracterização da região. $O$ autor indica as sete categorias fundamentais destas estruturas urbanas orientadas para o turismo (Mullins, 1991: 331):

i. Estas cidades são espacialmente diferentes, uma vez que estão construídas e orientadas para estratos sociais específicos, com formas arquitectónicas e estéticas que se associam aos destinatários finais, sendo o território fabricado no sentido da satisfação das possíveis orientações dos seus utilizadores finais. No caso do Algarve, a observação do território permitiu apresentar dois exemplos: Vilamoura, claramente orientada para classes sociais elevadas nacionais e estrangeiras, e por outro lado o centro urbano de Quarteira, marcado por edifícios em altura e apropriados por sectores sociais mais modestos, duas áreas que se encontram ligadas geograficamente mas que são profundamente diferenciadas.

ii. São simbolicamente distintas, usando um conjunto de ideologias como chamariz dos turistas, formas culturais profundamente marcadas por imagens de marca distintivas em relação a outras. Para ilustrar um pouco das estratégias usadas para promover o Algarve como espaço simbólico de evasão, apresentarei uma das campanhas mediáticas desenvolvidas pelo Turismo do Algarve, entidade de natureza mista (pública e privada) que promove a actividade na região. $\mathrm{O}$ turismo algarvio é apresentado como diversificado, um espaço para todos. Ao mesmo tempo tenta demonstrar a visibilidade da região no mundo, relevando o reconhecimento internacional do Turismo no Algarve ${ }^{8}$.

Você já ouviu falar dele. De certeza que algum amigo já lhe disse coisas como: Eu fui da praia à montanha num segundo, ou dei um passeio, observei pássaros e comi marisco, tudo na mesma tarde. É também provável que tenha lido sobre ele, que tenha encontrado numa revista um artigo a dizer que algumas das mais belas praias do mundo estão aqui e que até as estrelas do cinema já sabem disso. Ou, mais provável ainda, viu na televisão. Viu numa cadeia internacional um programa sobre a cultura, tradições e a história daquele que foi eleito o melhor destino de golfe do mundo.

iii. Como podemos perceber pela análise estatística aos números da região algarvia, estas cidades são marcadas por processos rápidos de aumento da população e da força de trabalho, através do crescimento natural e do incremento do fenómeno migratório resultantes da dinamização da actividade económica, dando-se um processo de especialização laboral directa e indirecta. Directa no conjunto de actividades económicas que se desenvolvem a partir do turismo, como a hotelaria e restauração, os serviços aeroportuários, a construção civil, as empresas de limpeza e jardinagem, ou as empresas de aluguer automóvel. Indirectamente, porque no momento em que as actividades ligadas ao 
Turismo se instalam numa região proporcionam um alargamento do mercado de trabalho, instalando-se outras actividades económicas na área dos serviços, alterando-se todo o território e as suas populações.

iv. A abundância contemporânea destas cidades materializa um conjunto de mudanças operadas na estrutura produtiva, promovendo um sistema flexível ao nível laboral e dos procedimentos, fomentando a criação de novas profissões e serviços, que se pode associar a um modelo de natureza pós-fordista. Essa transformação no Algarve poderá ser vista através do cruzamento dos Censos de 1960 e do Anuário Estatístico de 2010: diminuição de cerca de $84 \%$ dos trabalhadores dedicados à Agricultura e Pescas e aumento claríssimo no pessoal administrativo e similares (360\%), assim como no que toca aos trabalhadores dedicados aos serviços e comércio (153\%).

v. Estas cidades apresentam formas específicas de governo local, dotadas de alguma autonomia financeira e profundamente ligadas às redes de financiamento público e privado. No caso do Algarve, esta dinâmica não tem tanta força. Apesar da existência de alguns elementos fortes, nomeadamente o Presidente da Câmara Municipal de Faro (que também é presidente da Área Metropolitana do Algarve, AMAL), não poderemos dizer que existe um poder regional forte em relação ao todo nacional. A inexistência deste tipo de poderes está ligada ao carácter centralista dos processos de planeamento urbano em Portugal, tardando o processo constitucionalmente inscrito da Regionalização.

vi. Como espaço de consumo, orienta-se para um público-alvo, sendo de natureza massificada para classes sociais mais baixas e diferenciador para sectores sociais mais altos. Esta dinâmica foi explicada anteriormente com os casos de Vilamoura e Quarteira.

vii. A constituição destes espaços de lazer implica transformações nas populações locais, criando uma população socialmente distinta, resultante do contacto com os viajantes e do incremento migratório, em que o uso de uma segunda língua é generalizado; marcas de cosmopolitismo e de urbanidade que tradicionalmente são associadas às metrópoles globalizadas. Olhando para os dados estatísticos da população percebemos algumas marcas: número de casamentos entre estrangeiros e nacionais mais elevados na região, assim como uma progressiva entrada de residentes de nacionalidade estrangeira que escolhem esta zona da Europa do Sul como espaço de residência, particularmente no momento da reforma.

\section{Conclusões}

Neste texto pretendemos analisar os processos através dos quais uma determinada região é orientada de forma económica, social e cultural para a satisfação dos anseios de lazer de um conjunto de viajantes. Estas áreas urbanas turísticas tornam-se assim espaços de encontro lúdico, que pelas suas condições naturais (praias ou montanhas), condições patrimoniais (uso comercial de ruínas e edifícios de interesse estético e histórico), ou da criação de pólos de dinamização cultural e lúdica (criação de museus especializados, marinas de recreio, pontos de animação nocturna, parques temáticos) se reconvertem em espaços marcados pelas dinâmicas turísticas. Desta forma, as cidades e os seus protagonistas pretendem reconverter zonas fortemente empobrecidas, assim como boa parte do seu território antes consagrado à agricultura e pescas, reorientandoos para formas de alojamento temporário. Estes processos levantam a necessidade de orientar o nosso olhar para a importância dos instrumentos de planeamento e gestão partilhada do território, para a importância da participação pública dos vários agentes envolvidos e o desenvolvimento de processos de reconversão urbana marcados pela especialização turística. 
Ao mesmo tempo foi necessário perceber os efeitos que a introdução deste fenómeno trouxe à região, implicando a constituição de territórios marcados por elementos distintivos, materializando uma nova realidade urbana.

\section{BIBLIOGRAFIA}

BAPTISTA, L. (2005), “Territórios Lúdicos”, Forum Sociológico, 13/14, pp. 47-59.

BRITO, S. (2009), Território e Turismo no Algarve, Lisboa. Centro Internacional de Investigação em Território e Turismo da Universidade do Algarve/Edições Colibri.

BRYMAN, A. (2009), The Disneyization of Society, Los Angeles, Sage Publications.

DEBORD, G. (1997), A Sociedade do Espectáculo, Lisboa, Contraponto.

FORTUNA, C. e C. Ferreira (1996), “O Turismo, o Turista e A Pós-Modernidade”, Comunicação apresentada no Seminário "Reflexões sobre o Turismo", Faro.

GLADSTONE, D. (1998), “Tourism Urbanization in the United States”, Urban Affairs Review, 34 (1), pp. 3-27.

GLADSTONE, D. e S. Fainstein (1999), "Evaluating Urban Tourism”, in Dennis R. Judd e Susan S. Fainstein (eds.), Places to Play: the Remaking of Cities for Tourists, New Haven, Yale University Press, pp. 28-53.

HANNIGAN, J. (1995), “Tourism Urbanization”, Current Sociology, 43 (1), pp. 192-200.

HANNIGAN, J. (2010a), “Themed Environments”, in Ray Hutchison (ed.), Encyclopaedia of Urban Studies, Thousand Oaks, CA, Sage, pp. 805-809.

HANNIGAN, J. (2010b), “Urban Entertainment Destination”, in Ray Hutchison (ed.), Encyclopaedia of Urban Studies, Thousand Oaks, CA, Sage,

pp. 868-871.

INSTITUTO NACIONAL DE ESTATÍSTICA, INE, I. P. (1961), X Recenseamento Geral da População, Lisboa.

INSTITUTO NACIONAL DE ESTATÍSTICA, INE, I. P. (2011a), Anuário Estatístico da Região Algarve 2010, Lisboa.

INSTITUTO NACIONAL DE ESTATÍSTICA, INE, I. P. (2011b), Resultados Provisórios dos Censos 2011, disponível em http://www.ine.pt/xportal/xmain?xpid =INE\&xpgid=ine_main (acedido a 23 de Janeiro de 2011).

LEITE, N. (2008), Turismo e Território: Um estudo sobre a Turistificação de Portimão (Algarve/Portugal) a partir da Geografia do Turismo, Tese de Mestrado em Geografia na Universidade de Lisboa.

MULLINS, P. (1991), “Tourism Urbanization”, International Journal of Urban and Regional Research, 15 (3), pp. 326-342.

RITZER, G. (2010), Enchanting a Disenchanted World, Continuity and Change in the Cathedrals of Consumption, Londres, Sage. 
SOARES, A. (1997), A urbanística do lazer e do turismo no Algarve Litoral, Tese de Mestrado, Universidade de Lisboa.

TRIBE, J. (1997), “The Indiscipline of Tourism”, Annals of Tourism Research, 24 (3), pp. 638-657.

URRY, J. ([1991] 2002), The Tourist Gaze, Nottingham, Trent University.

\section{NOTAS}

1. Os Planos Municipais de Ordenamento do Território são instrumentos de gestão territorial promovidos pelo Decreto-Lei n. 69/90. Estes planos seriam divididos em: PDM, Plano Director Municipal; PU, Planos de Urbanização, e PP, Planos de Pormenor.

2. Um plano construído no sentido de travar os efeitos identificados como nefastos do turismo, um plano claramente restritivo da actividade. Na opinião do autor e que partilhamos, um plano construído contra a característica funcional principal da região, que fomentou a existência de habitação dispersa na região, assim como uma concentração excessiva da oferta turística nos locais indicados pelo plano.

3. Ao mesmo tempo a região concentra $16,21 \%$ de todos os imigrantes no território nacional, sendo que $19,55 \%$ dos ucranianos, $23,32 \%$ dos romenos e $30,9 \%$ dos moldavos residentes legalmente em Portugal estão concentrados no Algarve.

4. Que nos indica quais são os sectores que mais contribuem para o aumento dos lucros na região.

5. Medida que nos permite calcular o número máximo de pessoas a poderem ser alojadas num tipo de alojamento numa determinada área geográfica.

6. Tradução efectuada pelo autor.

7. Tradução efectuada pelo autor.

8. Retirado de http://www.youtube.com/watch?v=ObIFxrzOy8c (acedido a 23 de Janeiro de 2011).

\section{RESUMOS}

As cidades e os espaços de natureza urbana são comummente associados a territórios que expressam formas de dinamização produtiva (indústria, serviços), populacional (crescimento natural e migrações) e sociocultural (cosmopolitismo, interculturalidade). Com base na terciarização da economia em resposta a novas demandas, compreendendo os efeitos da diminuição dos horários de trabalho e o seu alargamento a sectores sociais mais diversificados, observando a reorientação do capital financeiro no sentido do lazer; percebemos que estão criadas as condições favoráveis à mercantilização da viagem de estanciar e a sua orientação para um ambiente de natureza urbana. Pretendemos discutir este processo iniciado na década de 1960 no Algarve. Estes territórios serão analisados como áreas urbanas polinucleares de orientação turística, uma região dedicada quase exclusivamente à recepção, acomodamento e diversão dos visitantes.

Cities and spaces of urban nature are commonly associated with territories where forms of productive (industry and services), population (natural growth and migrations) and sociocultural dynamics (cosmopolitism, interculturality) are expressed.

Based in the rising importance of the service economy in response to new demands, 
understanding the effects of the reduction of working hours and its extension to more diverse social sectors, noting the shift in financial capital regarding leisure, we find that conditions are favorable towards the commercialization of traveling and its orientation towards an environment of urban nature. We intend to discuss this process that started in the 1960's in the Algarve. These territories will be analyzed as polinuclear urban areas oriented towards tourism, a region devoted almost exclusively to the reception, accommodation and entertainment of visitors.

\section{ÍNDICE}

Keywords: Algarve, urbanization, tourism, leisure

Palavras-chave: Algarve, urbanização, turismo, lazer

\section{AUTOR}

\section{JOÃO MARTINS}

Doutorando em Sociologia Urbana, do Território e do Ambiente na FCSH-UNL/CesNova e bolseiro FCT,

joaomartins.cf@fcsh.unl.pt 